\title{
Use of Capecitabine in Refractory Metastatic Medullary Thyroid Carcinoma
}

\section{Dear Editor:}

Medullary thyroid carcinoma (MTC), an uncommon tumor that occurs in $\sim 5 \%$ of thyroid cancers, responds poorly to nonsurgical therapy $(1,2)$. Radioactive iodine does not concentrate in MTC cells and chemotherapy is often disappointing (1). Doxorubicin is frequently used, however, the response rate is around $10 \%$ to $20 \%$ of the cases (2). In metastatic MTC, the National Cancer Care Network (NCCN) recommends dacarbazine-based therapy, supported by small studies $(1,3)$. Additionally, due to the lack of data regarding outcome alteration, the NCCN suggests including the patient in a clinical trial (1). Sorafenib, an oral agent that selectively targets RET tyrosine kinases, represents a particularly promising drug (4), but its routine use needs further studies.

We report a 37-year-old Brazilian man diagnosed in December 2003 with MTC (pT3pN1M0) who underwent total thyroidectomy and lymph node dissection with adjuvant radiation. In December 2004 he presented locally unresectable recurrence and was submitted to palliative chemotherapy (dacarbazin $200 \mathrm{mg} / \mathrm{m}^{2}$, IV, days 1 to 5 plus fluorouracil $450 \mathrm{mg} / \mathrm{m}^{2}, \mathrm{IV}$, days 1 to 5 , in a 3-weekly regimen). With the disease progression after 12 months, second-line chemotherapy was performed with doxorubicin $\left(75 \mathrm{mg} / \mathrm{m}^{2}, \mathrm{IV}\right.$, day 1 , a 3-weekly regimen, during seven cycles). In January 2007, oral capecitabine $\left(1000 \mathrm{mg} / \mathrm{m}^{2}\right.$, twice daily, on days 1 to 14 ) was started in a 3-weekly regimen because of bulky cervical, mediastinal, left axillary, diffuse lung nodules and dry cough, weight loss, watery diarrhea, and cervical pain. After four cycles of capecitabine, he showed remarkable symptomatic improvement with decreased diarrhea and pain, enhanced appetite, and lower carcinoembriogenic (CEA) level. He is now undergoing the eighth cycle of capecitabine with disease stabilization as shown by tumor diameters on clinical exams and chest radiograph, stable CEA level, better quality of life, and just one episode of grade- 1 hand-foot syndrome.
Recently, Gilliam et al. (5) reported three patients diagnosed with metastatic MTC and treated with oral capecitabine, which is converted to the active metabolite 5-fluorouracil, preferentially in malignant tissues, by thymidylate phosphorylase. The authors found two patients with disease response and one of them with marked decrease in CEA level. These findings suggest that capecitabine is a reasonable option with clinical benefit, disease stabilization, and tolerable adverse effects.

Carlos Eduardo Paiva, M.D. Odair Carlito Michelin, M.D., Ph.D.

Oncological and Hemato-oncological Center São Paulo State University Botucatu, SP, Brazil

\section{References}

1. National Comprehensive Cancer Center Network Clinical Practice Guidelines in Oncology: Thyroid Carcinoma. Version 2.2007. <http://www.nccn.org/professionals/physician_gls/ PDF/thyroid.pdf $>$. Accessed June 11, 2007.

2. Martins RG, Rajendran JG, Capell P, Byrd DR, Mankoff DA 2006 Medullary thyroid cancer: options for systemic therapy of metastatic disease? J Clin Oncol 11:1653-1655.

3. Nocera M, Baudin E, Pellegriti G, Cailleux AF, MechelanyCorone C, Schlumberger M 2000 Treatment of advanced medullary thyroid cancer with an alternating combination of doxorubicin-streptozocin and 5 FU-dacarbazine. Groupe $\mathrm{d}^{\prime}$ Etude des Tumeurs a Calcitonine (GETC). Br J Cancer 83: 715-718.

4. Kober F, Hermann M, Handler A, Krotla G 2007 Effect of sorafenib in symptomatic metastatic medullary thyroid cancer. Proc Am Soc Clin Oncol 25:14065.

5. Gilliam LK, Kohn AM, Lalani T, Swanson PE, Vasko V, Patel A, Livingston RB, Pickett CA 2006 Capecitabine therapy for refractory metastatic thyroid carcinoma: a case series. Thyroid 16:801-810. 

This article has been cited by:

1. Masahiro Sugawara, Tran Ly, Jerome M. Hershman. 2012. Medullary Thyroid Cancer-Current Treatment Strategy, Novel Therapies and Perspectives for the Future. Hormones and Cancer 3:5-6, 218-226. [CrossRef]

2. Andrea Conway, Andres Wiernik, Ajay Rawal, Cornelius Lam, Hector Mesa. 2012. Occult Primary Medullary Thyroid Carcinoma Presenting with Pituitary and Parotid Metastases: Case Report and Review of the Literature. Endocrine Pathology 23:2, 115-122. [CrossRef]

3. Masahiro Sugawara, David L Geffner, Dorothy Martinez, Jerome M Hershman. 2009. Novel treatment of medullary thyroid cancer. Current Opinion in Endocrinology, Diabetes and Obesity 16:5, 367-372. [CrossRef] 